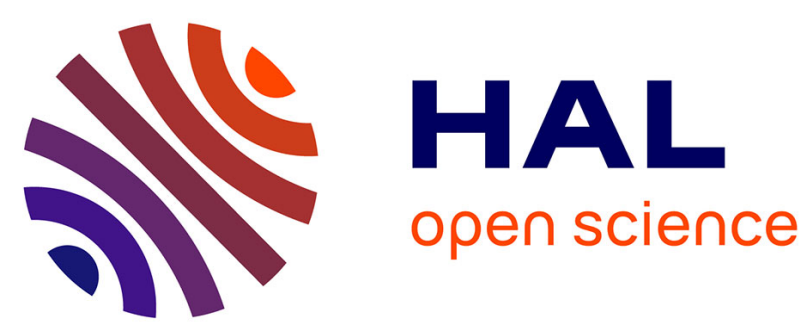

\title{
New visualization tools for designers to identify bio-based plastic substitutes considering carbon footprint and key material properties
}

\author{
Michael Saidani, Erik Pan, Keith Ng, Harrison Kim
}

\section{- To cite this version:}

Michael Saidani, Erik Pan, Keith Ng, Harrison Kim. New visualization tools for designers to identify bio-based plastic substitutes considering carbon footprint and key material properties. ASME 2020 International Design Engineering Technical Conferences and Computers and Information in Engineering Conference, Aug 2020, St Louis, United States. hal-02995126

\author{
HAL Id: hal-02995126 \\ https://hal.science/hal-02995126
}

Submitted on 18 Nov 2020

HAL is a multi-disciplinary open access archive for the deposit and dissemination of scientific research documents, whether they are published or not. The documents may come from teaching and research institutions in France or abroad, or from public or private research centers.
L'archive ouverte pluridisciplinaire HAL, est destinée au dépôt et à la diffusion de documents scientifiques de niveau recherche, publiés ou non, émanant des établissements d'enseignement et de recherche français ou étrangers, des laboratoires publics ou privés. 


\title{
NEW VISUALIZATION TOOLS FOR DESIGNERS TO IDENTIFY BIO-BASED PLASTIC SUBSTITUTES CONSIDERING CARBON FOOTPRINT AND KEY MATERIAL PROPERTIES
}

\author{
Michael Saidani ${ }^{1}$, Erik Pan, Keith Ng, Harrison Kim \\ Department of Industrial and Enterprise Systems Engineering, \\ University of Illinois at Urbana-Champaign, Illinois, USA
}

\section{SYNOPSIS FOR THE DESIGN TOOL SHOWCASE}

Novel bio-based plastics appear to be a timely alternative to conventional - petroleum-based - plastics in order to face pressing issues such as plastic pollution [1]. Yet, their actual adoption in new product development needs to be augmented. As the design phase has a key influence on the sustainable performance of products over their lifecycle [2], providing designers with appropriate and practical tools for green material selection is of the utmost importance. Particularly, integrated visualization-based tools can effectively support designers and material engineers in the screening and selection of sustainable alternatives during the design and development process [3].

To bridge the gap of existing tools and associated databases that unsatisfactorily address the comparison between bio-based plastics and their petroleum-based counterparts, two new visualization tools are developed. To build these tools, the following approach and resources have been used: (i) a review of state-of-the-art articles on bio-based plastics to extract information about their performance; (ii) a critical analysis of existing visualization-based tools to get inspiration, and to know what features are valued or useful for engineers; and (iii), iterative interactions, through surveys and focus groups, with designers and material engineers from a manufacturer of agricultural equipment interested in finding suitable bio-based materials for the products they develop [4].

While these two tools can be deployed independently of one another, they are also complementary in the way that: (i) the first tool enables a first and rapid screening of potentially suitable biobased alternatives, considering, e.g., their cost, availability, carbon footprint, and key material properties; and (ii) the second tool allows to dive further into the material selection process by providing more materials and information to display. Interestingly, different formats have been preferred to design the two tools: a physical prototype tool (Figs. 1-2) that can also be viewed on a screen (Fig. 3), and a web-based tool (Fig. 4).
The first tool (Figs. 1-3) combines the valued features of several separate visualization tools (e.g., quantitative bar chart, contrasting colors, multi-dimensional representation, logos) in an integrated way. This graphical visual interface representing multi-dimensional information can be viewed as an infographic, that can either (i) be printed and posted on design and material engineers desktop to inform them on bio-based plastics alternatives, or (ii) be displayed on a computer screen. Such a visual is relevant to communicate easy-to-digest and easy-tounderstand information for designers that might not be specifically trained for sustainable material selection or familiar with other tools like life cycle assessment software.

The second visualization-based tool (Fig. 4), the Sustainable Material Advisor - accessible through the following link: https://ericpzh.github.io/smaterialsadvisor/ - is a web-based app built using the React JS framework. The front-end-only app is mainly built based on the data provided by Idemat. The user interface is implemented using components from Semantic UI, and the interactive plot is implemented using Plotly. A snapshot of this tool is available in Figure 4, and the functionalities of its user interface for material screening are described in Table 1.

\section{PROPOSED SETUP FOR THE DEMONSTRATION}

To present these novel visual tools to the design community, a printed poster of the first tool (Fig.1 and/or Fig. 2) is expected to be displayed at the stand, and handouts will be made available for the attendees. Also, an interactive computer-based version of this first tool (Fig. 3) is being developed to highlight and identify more easily the materials that meet the desired requirements.

Like the 2019 Design Tool Showcase [5] (demonstrating a web-based platform for circularity indicators [6]), a computer will be made available for the interested participants to experience both tools - either on their own projects or on one of the two case studies provided - to demonstrate the usefulness of such tools to screen bio-based plastic substitutes in practice.

\footnotetext{
${ }^{1}$ Contact author: msaidani@illinois.edu
} 


\section{ILLUSTRATIONS OF THE TOOLS}

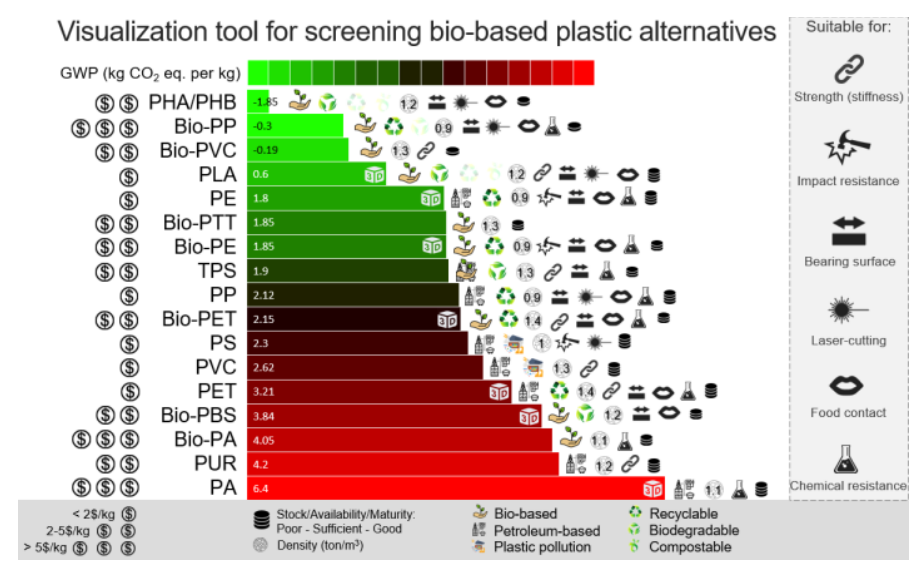

FIGURE 1: NEWLY DEVELOPED VISUALIZATION TOOL*

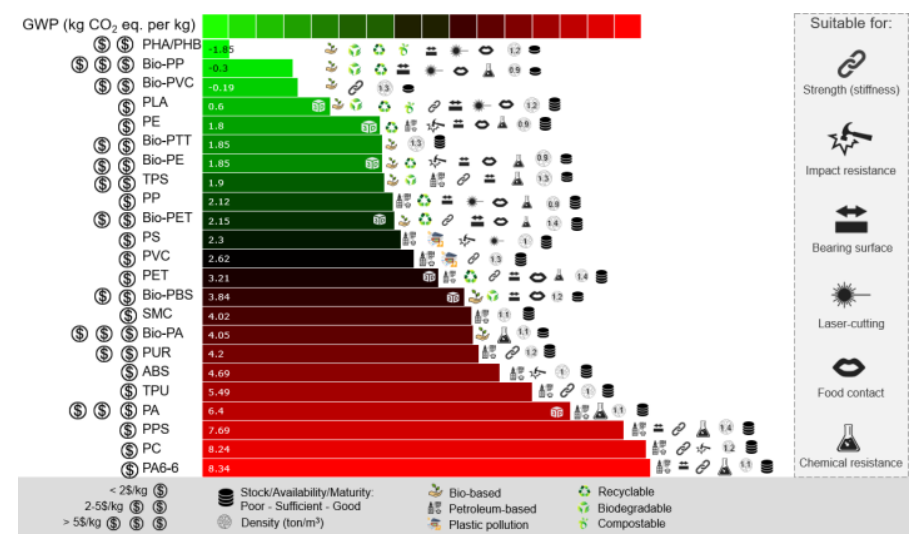

FIGURE 2: AUGMENTED VERSION WITH MORE PLASTICS

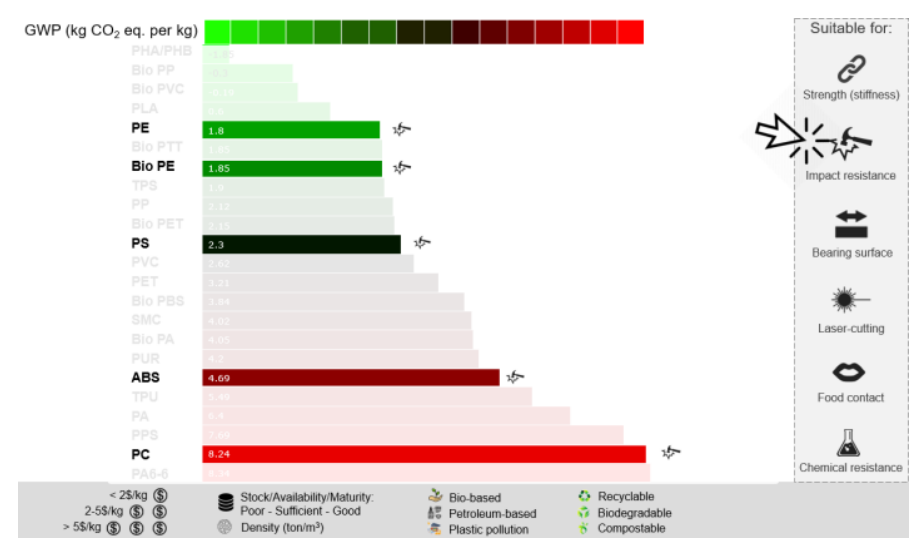

FIGURE 3: PROTOTYPE OF AN INTERACTIVE VERSION

*Colorblind-friendly versions of this tool are available ondemand, including blue/orange and turquoise/purple gradientfilled palettes.

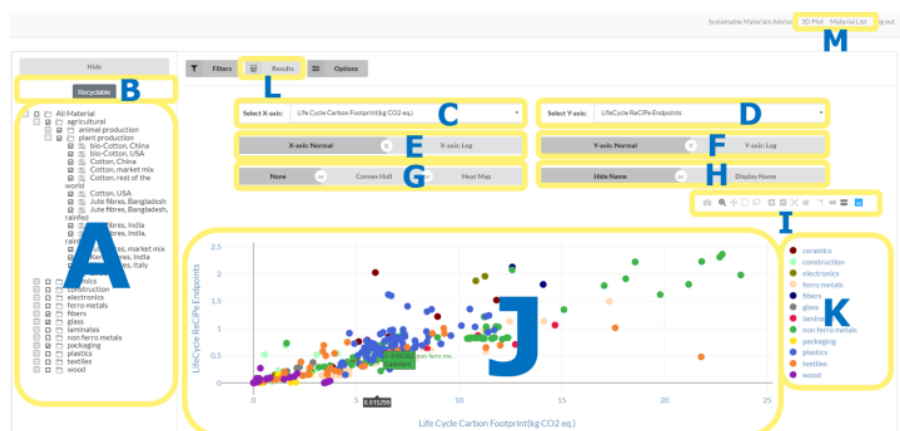

FIGURE 4: OVERVIEW OF THE S-MATERIALS ADVISOR

TABLE 1: NOMENCLATURE OF THE AVAILABLE FEATURES

\begin{tabular}{|l|l|}
\hline$\#$ & Description and functionalities of the user interface \\
\hline A & $\begin{array}{l}\text { Material selection and filter (filter out, material organized by } \\
\text { tree structure) }\end{array}$ \\
\hline B & $\begin{array}{l}\text { Preset filters (one-click filter base on preset category, e.g. on a } \\
\text { particular feature, supplier, etc.) }\end{array}$ \\
\hline C & $\begin{array}{l}\text { X-axis category selector (selection between impact and cost } \\
\text { metrics) }\end{array}$ \\
\hline D & Y-axis category selector (same as above) \\
\hline E & X-axis scale selector (normal or log scale) \\
\hline F & Y-axis scale selector (same as above) \\
\hline G & $\begin{array}{l}\text { Overlay mode selector (choose between convey hull of } \\
\text { category or heat map) }\end{array}$ \\
\hline H & Display material name toggler \\
\hline I & $\begin{array}{l}\text { Graph functions (zoom, box/lasso selection filter, save as a png } \\
\text { file) }\end{array}$ \\
\hline J & $\begin{array}{l}\text { Graph area (hover the mouse pointer over the points to display } \\
\text { detailed information) }\end{array}$ \\
\hline K & Legend area (click to make material groups (dis)appear) \\
\hline L & $\begin{array}{l}\text { Results "pop-up window" (click to quick summary the best } \\
\text { material(s) (impact metrics, cost) in each category) }\end{array}$ \\
\hline M & Link to a 3-dimension graph and list of materials \\
\hline
\end{tabular}

\section{REFERENCES}

[1] Spierling, S., et al. (2018). "Bio-based plastics - A review of environmental, social and economic impact assessments". Journal of Cleaner Production, 185, pp. 476-491.

[2] Ramani, K., Ramanujan, D., Bernstein, W. Z., et al. (2010). "Integrated Sustainable Life Cycle Design: A Review". Journal of Mechanical Design, 132(8), pp. 1-15.

[3] Ramanujan, D., Bernstein, W.Z., Chandrasegaran, S. K., and Ramani, K. (2017). "Visual Analytics Tools for Sustainable Lifecycle Design: Current Status, Challenges, and Future Opportunities". Journal of Mechanical Design, 139(11).

[4] Saidani, M., Pan, E., and Kim, H. M. (2020). "Switching from petroleum- to bio-based plastics: visualization tools to screen sustainable material alternatives during the design process". ASME IDETC/CIE 2020, St. Louis, MO, USA.

[5] Saidani, M., Kim, H. M., Yannou, B., Leroy, Y., and Cluzel, F. (2019). "C-indicators: a web-based platform to monitor and improve the circularity potential of products". ASME IDETC/CIE 2019, Anaheim, CA, USA.

[6] Saidani, M., Yannou, B., Leroy, Y., Cluzel, F., and Kendall, A. (2019). "A taxonomy of circular economy indicators". Journal of Cleaner Production, 207, pp. 542-559. 